\title{
A LINGUAGEM EMOCIONAL NA PRÁTICA DOCENTE ONLINE: IMPLICAÇÕES EDUCACIONAIS COTIDIANAS
}

THE EMOTIONAL LANGUAGE IN ONLINE TEACHING:

EVERYDAY EDUCATIONAL IMPLICATIONS

\section{EL LENGUAJE EMOCIONAL EN PRÁCTICA DOCENTE EN LÍNEA: IMPLICACIONES EDUCACIONALES COTIDIANAS}

\section{Caroline Costa Nunes Lima ${ }^{1}$ \\ Felipe Silva Ponte Carvalho Dilton Ribeiro Couto Junior ${ }^{3}$}

\begin{abstract}
RESUMO: Este artigo é fruto de pesquisa recentemente concluída que se propôs a investigar as implicações teórico-práticas da linguagem emocional na docência online. Em relação aos procedimentos metodológicos, docentes online foram convidados a compartilhar relatos de experiências focalizando seus trabalhos desenvolvidos cotidianamente nos ambientes virtuais de aprendizagem (AVA). Para isso, a abordagem teóricometodológica dos estudos com os cotidianos nos auxiliaram a interpretar os relatos produzidos pelos sujeitos. Alguns dos achados dos estudos incluíram a necessidade de (re)pensar o papel do docente online na cibercultura e o uso da linguagem emocional como mediadora nos AVA com a intenção de propiciar o fortalecimento das relações interpessoais construídas nesse espaço. Diante do exposto, este estudo reflete nosso interesse em torno do papel do docente na tarefa de contribuir para uma educação online que coloque em prática uma abordagem pedagógica dialógica com o intuito de enriquecer a experiência educacional.
\end{abstract}

PALAVRAS-CHAVE: Cibercultura. Pesquisa com os cotidianos. Linguagem emocional. Docência online.

ABSTRACT: This article is the result of a recently concluded research that aimed to investigate the theoreticalpractical implications of emotional language in online teaching. Regarding methodological procedures, online teachers were invited to share experiences focusing on their daily work in virtual learning environments (VLE). For this, the theoretical-methodological approach of the studies with the quotidian helped us to interpret the reports produced by the subjects. Some of the findings of the studies included the need to (re)think the role of the online teacher in cyberculture and the use of emotional language as mediator in the VLE with the intention of fostering the interpersonal relationships built in this space. In view of the above, this study reflects our interest in the mediating role of teachers in the task of contributing to an online education that puts into practice a dialogical pedagogical approach in order to enrich the educational experience.

KEYWORDS: Cyberculture. Research with the quotidian. Emotional language. Online teaching.

RESUMEN: Este artículo es consecuencia de una investigación reciente que se apoya en las implicaciones teóricas-prácticas de la lingüística emocional en línea. En relación a los procedimientos metodológicos, docentes en línea fueron convidados a compartir relatos de experiencias diarias a respeto de sus trabajos desarrollados nos ambientes virtuales de aprendizaje (AVA). Para eso un abordaje teórico-metodológico dos estudios con los cotidianos nos auxiliaron a interpretar los relatos producidos pelos sujetos. Alguno de los dos requisitos incluidos incluye una necesidad de (re) pensar el papel del docente en línea en la cibercultura y el uso del lenguaje emocional como mediadora nos AVA con un propósito de apoyo o fortalecimiento de las relaciones interpersonales construidas en el espacio libre. Delante do expuesto, este estudio reflejado nos interesan en torno

Submetido em: 07/04/2018 - Aceito em: 20/05/2018 - Publicado em: 29/05/2018.

\begin{tabular}{l|l|l|l|l|l} 
(C) Rev. Inter. Educ. Sup. & Campinas, SP & v.4 & n.3 & p.542-557 & set./dez. 2018
\end{tabular}


al papel docente en tarea de contribuir para la educación en línea que lo ponga en práctica una abordaje pedagógica dialógica con intuito de enriquecer a experiencia educacional.

PAlABRAS ClaveS: Cibercultura. Pesquisa con los cotidianos. Lenguaje emocional. Docencia en línea.

\section{LINGUAGEM EMOCIONAL NA EDUCAÇÃO ONLINE: INICIANDO O DEBATE}

As tecnologias da informação e comunicação estão modificando nossa relação com o mundo, reconfigurando todas as esferas da sociedade, dos meios de produção ao consumo cultural (SANTAELLA, 2003). A emergência das interfaces digitais possibilitou que os sujeitos participassem de práticas colaborativas interativas, evidenciando a necessidade da arquitetura hipertextual da internet na constituição de processos comunicacionais em rede envolvendo sujeitos geograficamente dispersos. Essas práticas interativas são possíveis devido à "liberação da palavra", um dos princípios da cibercultura que caracteriza a forma com a qual os sujeitos deixam de ocupar o papel de meros consumidores culturais dos meios e passam a agir como consumidores que também produzem ativamente novos conteúdos digitais na rede mundial de computadores (LEMOS, 2010). No cenário sócio-técnico contemporâneo, com amplas e dinâmicas formas de entrar em contato com o outro, não há como negar a "importância política da liberdade de expressão promovida pelas interfaces fáceis e baratas" (PRIMO, 2013, p. 17). Aplicativos, redes sociais digitais, wikis, mobilidade, ubiquidade, dentre muitos outros termos, ilustram uma época nitidamente marcada pelas práticas sociais ciberculturais.

Desde o final do século XX, principalmente com a chegada da primeira edição da obra Cibercultura (LÉVY, 1999) ao mercado brasileiro, inúmeros estudos vêm se dedicando a investigar os fenômenos sociais engendrados pela relação dos sujeitos com as tecnologias digitais em rede. A cibercultura na vida social contemporânea (LEMOS, 2002), cultura da convergência (JENKINS, 2009), movimentos sociais na era da internet (CASTELLS, 2013), conversação mediada pelo computador (RECUERO, 2012), ciberdemocracia planetária (LEMOS; LÉVY, 2010) e redes sociais digitais (SANTAELLA; LEMOS, 2010; RECUERO, 2013), para citar alguns, constituem-se alguns dos temas estudados no campo de estudos da cibercultura. Na área educacional, não poderíamos deixar de mencionar as pesquisas que focalizaram seus esforços investigativos nos processos de ensinar-aprender no contexto das redes sociais digitais (COUTO JUNIOR, 2013), na produção de conhecimento mediada por dispositivos digitais móveis (FERREIRA, 2014; SANTOS, 2011), no uso de aplicativos (app) com fins pedagógicos (NETO; VERSUTI; VAZ, 2016; OLIVEIRA; MERCADO, 2016; BENTO; VENAS, 2016), na relação entre escola e tecnologias digitais em rede (BONILLA, 2009; ARRUDA, 2009) e na mediação online realizada entre praticantes culturais nos ambientes virtuais de aprendizagem (AVA) (SANTOS; CARVALHO; PIMENTEL, 2016; SANTOS, 2010). 
O panorama de pesquisas acima mencionado evidencia que os processos comunicacionais digitais em tempos de cibercultura constituem-se enquanto parte das práticas culturais contemporâneas. Através do uso de interfaces digitais gratuitas, esses processos comunicacionais na/em rede possibilitam aos usuários estabelecer vínculos sociais e afetivos em prol da construção de "um espaço de formação pautado em lógicas não-lineares, na aprendizagem colaborativa, na interatividade, na multivocalidade, nas dinâmicas das redes. Um espaço vivo de criação, de produção, de comunicação e, portanto, um espaço de cultura[s]" (PRETTO; BONILLA, 2008, p. 86). Dito isso, com as tecnologias digitais em rede, cenário no qual a educação online se pratica, há uma disponibilidade de meios (batepapo, fórum de discussão, redes sociais, aplicativos (app), para citar alguns) capazes de conectar pessoas geograficamente dispersas que podem partilhar informações, construir saberes coletivamente com espaço para criatividade e proatividade (SANTOS, 2002, 2009; SANTOS; CARVALHO; PIMENTEL, 2016). Não há como negar que as práticas sociais cada vez mais mediadas pelas tecnologias digitais vêm res-significando a forma de se trabalhar os diferentes conhecimentos no cotidiano escolar e isso demanda a necessidade de que sejam investigados os processos de ensinar-aprender que se abrem com o digital em rede.

Neste texto, fruto de pesquisa recentemente concluída, nos propusemos a investigar as implicações teórico-práticas da linguagem emocional na docência online. Defendemos uma educação online que reconheça as potencialidades interativas das mídias digitais (SILVA, 2009), ou seja, nos inspiramos no digital em rede para: 1) colocar em prática uma educação baseada na interatividade (todos $\mathrm{x}$ todos), contrapondo o modelo de comunicação massiva unidirecional (um x todos); 2) fazer uso do potencial que as redes digitais disponibilizam para a promoção da autoria e; 3) mediar os discentes para o uso ético, cidadão e responsável das interfaces digitais. Atuar como docente online é estar imerso na cibercultura através da partilha de sentidos produzidos entre sujeitos que buscam novas formas de entrar em contato com os conhecimentos. Sem esse caminhar, corre-se o risco de adotarmos as interfaces comunicacionais digitais dentro da perspectiva da pedagogia da transmissão, com os processos de ensino-aprendizagem ancorados na "educação bancária" (FREIRE, 2005) que tanto ainda continuamos lutando para romper.

A linguagem, seja ela em sua forma corporal, oral ou escrita, tem estreita relação entre o pensamento, conhecimento, expressão, emoção e comunicação. A linguagem, responsável por (re)ações manifestadas no convívio social, é constituinte de um processo interativo entre duas ou mais pessoas que negociam permanentemente sentidos (RECUERO, 2012). O conceito de linguagem emocional adotado neste trabalho diz respeito às "múltiplas formas em que os seres humanos estabelecem relações, utilizando-se das diversas linguagens, considerando o fator emocional como importante desencadeador das transformações decorrentes neste processo" (BRUNO, 2002, p. 203). Dessa forma, a linguagem emocional é um meio para que os sujeitos expressem/comuniquem emoções através de processos conversacionais contínuos que permitem possibilidades interativas e de transformação de si e do outro (BRUNO, 2002).

\begin{tabular}{|l|l|l|l|l|l|}
\hline (C) Rev. Inter. Educ. Sup. & Campinas, SP & v.4 & n.3 & p.542-557 & set./dez. 2018 \\
\hline
\end{tabular}


$\mathrm{O}$ aspecto emocional na interação entre sujeitos requer reconhecimento e legitimidade na prática pedagógica cotidiana, pois a linguagem não é meramente um processo mecânico interativo que busca o "sim" ou o "não", tampouco o "certo" ou o "errado". Pelo contrário, o diálogo entre duas ou mais pessoas é uma forma "criativa e produtiva do eu se aproximar com suas palavras às palavras do outro, construindo uma compreensão que, por não ser de mero reconhecimento dos signos usados, é sempre uma proposta, uma oferta, uma resposta aberta a negociações e a novas construções" (GERALDI, 2013, p. 15). Frente a isso, cabe questionarmos: quais processos dialógicos se abrem com as potencialidades comunicacionais do digital em rede? E o que somos capazes de ensinar ao mesmo tempo em que também nos colocamos abertos e disponíveis para aprender com o outro?

Bruno (2002, p. 15) apresenta algumas reflexões importantes sobre a linguagem emocional no contexto da docência online. De acordo com a autora,

\begin{abstract}
Nos ambientes telemáticos [junção dos recursos tecnológicos das telecomunicações e da informática], a observação corporal ainda é restrita/limitada. Por nos utilizarmos, em grande parte dos casos, da comunicação por meio da linguagem escrita, os aspectos corporais observáveis, que envolvem olhar, expressão oral, gestual, tátil, tornam se inviáveis. Portanto, há necessidade de que os professores nesses ambientes dediquem especial atenção às comunicações escritas dos alunos, expressas pela Linguagem Emocional no processo de interação.
\end{abstract}

Diante dos limites da observação corporal nos AVA (BRUNO, 2002), reiteramos a importância da comunicação escrita no processo de interação entre os sujeitos para que os laços afetivos sejam fortalecidos na medida em que a comunicação ocorre. Ao fazer uso da linguagem emocional no ambiente online, o docente coloca em prática um olhar sensível para com o grupo de estudantes com quem irá partilhar o conhecimento, não existindo "receitas prontas" ou o "melhor caminho" para o modo como as palavras serão enunciadas. Ao reconhecermos que a palavra do outro nos coloca diante do desafio de interpretá-la (BAKHTIN, 2011), consideramos o quão imprescindível é o olhar atento e respeitoso para a forma como interagimos cotidianamente. Com as palavras exprimimos as mais diversas emoções, colocando-nos abertos ao dar-se a conhecer através das diferentes possibilidades dialógicas que se abrem nas conversas estabelecidas com outros praticantes culturais. Além de buscar assegurar a formação acadêmica de qualidade, o docente online agrega em sua postura o desempenho de uma prática reflexiva, sensível, colaborativa e crítica, sem deixar de desenvolver com os estudantes os aspectos afetivo-emocionais engendrados na/pela linguagem. 


\section{OS ESTUDOS COM OS COTIDIANOS: CONSIDERAÇÕES SOBRE A METODOLOGIA DA PESQUISA}

A abordagem metodológica-epistemológica adotada neste estudo é baseada nas pesquisas com os cotidianos, a partir das contribuições de Alves (2001, 2003) e Oliveira (2007). De acordo com Alves (2003), nessa abordagem o modo de fazer pesquisa requer a) o envolvimento do pesquisador com seus interlocutores de pesquisa; b) compreender os sujeitos como seres pensantes, produtores culturais; c) comunicar novas preocupações, novos problemas, novos fatos e novos achados que os acontecimentos nos trazem; e, por fim, d) fazse necessário pesquisar através de "um mergulho com todos os sentidos no que desejamos estudar" (ALVES, 2003, p. 3). Essa abordagem parte do pressuposto que os participantes da pesquisa são produtores de cultura e não meros reprodutores-informantes, a relação entre pesquisador e sujeitos é intensa, colaborativa e não há distanciamento entre sujeito-objeto, como propõe a racionalidade científica moderna (ALVES, 2003). Somando-se a isso, os estudos com os cotidianos argumentam que captar no campo empírico "seu dinamismo, seus enredamentos, seus pequenos acontecimentos torna-se meio fundamental para o encontro do imprevisível, do incontrolável, do diverso, do singular que também fazem parte da vida cotidiana e de aprendizagem sobre o mundo" (OLIVEIRA, 2007, p. 122-123).

Pesquisar no contexto das práticas sociais mediadas pelas tecnologias digitais em rede significa legitimar a internet como "lugar de encontro que permite a formação de comunidades, grupos estáveis e a emergência de novas formas de sociabilidade" (MERCADO, 2012, p. 167). Ao adotarmos as tecnologias digitais como parte dos procedimentos metodológicos, estamos reconhecendo-as como constituintes das práticas culturais de usuários que participam ativamente de processos de interação com outras pessoas geograficamente dispersas. Pesquisar através da abordagem metodológica-epistemológica dos estudos com os cotidianos nos convida a lançar um olhar atento e sensível para o campo empírico. Conforme nos lembra Alves (2001), esse olhar exige a criação de um sentimento de disponibilidade e cumplicidade para o diálogo com o outro, fazendo com que o pesquisador seja capaz de colocar em prática uma postura que vá "muito além do olhar que vê, com o qual aprendemos a trabalhar. É preciso entender, assim, que o trabalho a desenvolver exigirá o estabelecimento de múltiplas redes de relações" (ALVES, 2001, p. 21-22) tecidas entre pesquisador e sujeitos.

A abordagem dos estudos com os cotidianos tornou possível uma melhor compreensão da complexidade da linguagem emocional nas práticas da docência online da disciplina "Informática na Educação", do curso de Pedagogia a distância da Universidade do Estado do Rio de Janeiro (CEDERJ/UAB/UERJ) no primeiro semestre de 2017. Após apresentar a proposta de pesquisa, o contato com os participantes propiciou conhecer sobre como eles começaram a tutoria, qual sua formação acadêmica e tempo de atuação na função de docente 
online. Na medida em que os laços sociais e afetivos iam se estreitando na conversa, foram trocadas experiências sobre as atividades cotidianas nos AVA. Por meio de mensagem "inbox" na rede social Facebook, foram convidados docentes online da disciplina "Informática na Educação" que atuavam no consórcio UERJ/CEDERJ/UAB3. Posteriormente, a pesquisa de campo se estendeu, passando a contar com a participação de tutores docentes online do Laboratório de Novas Tecnologias de Ensino da Universidade Federal Fluminense (UFF). Para ampliar o número de sujeitos participantes da investigação, adotou-se como procedimento metodológico uma chamada no Facebook que informava sobre o tema e o objetivo do estudo4. Essa chamada era voltada para que docentes tutores a distância discutissem sobre suas experiências educacionais nos AVA.

O trabalho de campo possibilitou compreender mais amplamente o contexto em que esses profissionais atuavam, o cenário em que aconteciam suas mediações, seus anseios, expectativas, necessidades de sentirem-se valorizados e preocupações pela regulamentação da função de docente online. Investigar essas questões fazem-se necessárias visto que é comum a preocupação com o foco no aluno, quando a figura do docente online tutor por vezes fica em segundo plano, sobrecarregados e inseguros diante de tantos desafios e responsabilidades. Neste contexto, concordamos com Santos (2010), que revela a importância da relação com o outro no estabelecimento de aprendizagens-ensinamentos colaborativos. De acordo com a autora, "acreditamos que aprendemos mais e melhor quando temos a provocação do 'outro' com sua inteligência, sua experiência. Sabemos que temos interfaces [digitais] que garantirão a nossa comunicação com nossa fala livre e plural" (SANTOS, 2010, p. 47). Dito isso, longe de buscar fornecer a "última palavra" às questões levantadas durante a interação com os sujeitos participantes do estudo, os desafios discutidos não apresentam respostas definitivas ou soluções conclusivas, apenas pistas que emergiram a partir das provocações desencadeadas pelo intercâmbio de experiências.

\section{ANÁLISE INTERPRETATIVA: RELATOS DA DOCÊNCIA ONLINE}

A partir do trabalho de campo conduzido em 2017, foram recebidos relatos de profissionais do campo da educação que atuam no trabalho com as tecnologias da informação e comunicação. Esses relatos trazem elementos reflexivos importantes de experiências partilhadas frutos da linguagem emocional praticada na educação online. Vale destacar que

\footnotetext{
${ }^{2}$ Trata-se de uma caixa de bate-papo em que se troca de modo privado mensagens de texto, arquivos, fotos ou links.

${ }^{3}$ Esse consórcio é formado por seis universidades públicas do Estado do Rio de Janeiro que, em parceria Secretaria de Estado de Ciência, Tecnologia e Inovação do Rio de Janeiro, tem por objetivo a oferta de cursos de graduação a distância na modalidade semipresencial contando com polos por vários municípios do Estado do Rio de Janeiro.

${ }^{4}$ Essa chamada foi publicada na rede social da primeira autora do texto, responsável pela condução do trabalho de campo. O segundo autor do texto orientou a pesquisa em questão.

\begin{tabular}{l|c|c|c|c|c} 
(C) Rev. Inter. Educ. Sup. & Campinas, SP & v.4 & n.3 & p.542-557 & set./dez. 2018 \\
\hline
\end{tabular}
}


optamos pelo uso de pseudônimos para identificar as participantes do estudo, preservando, desta forma, a identidade dos sujeitos.

A seguir apresentamos trechos dos depoimentos de três sujeitos participantes do estudo de campo: Maria, formada em Psicologia, com mestrado e doutorado na mesma área, especialista em $\mathrm{EaD}$ e tem experiência em produção de materiais didáticos e docência online no consórcio CEDERJ/CECIERJ, pela Universidade Aberta do Brasil (UAB) e em capacitações em Organizações Não Governamentais (ONGs); D. K, aluna de mestrado em psicologia na UNISINOS/RS, cuja pesquisa é voltada para a prática pedagógica de tutores de ensino superior a distância em todo país; e Cíntia, atua como docente online na disciplina Informática na Educação, no curso de Pedagogia da UERJ, e é aluna do curso de especialização a distância em Planejamento, Implementação e Gestão da EaD (PIGEAD) na UFF. Diante da extensão dos depoimentos enviados pelas profissionais, optamos pela realização de uma edição objetivando destacar melhor os aspectos concernentes à linguagem emocional.

\begin{abstract}
Maria: Num curso de pós-graduação financiado pela UAB, era responsável pela mediação do ensino de 30 alunos por vez, o que me permitia estar realmente presente na aprendizagem deles. Era um projeto que me motivava muito e no qual via realmente a maior parte dos princípios da EaD serem colocados em prática. Percebi que uma aluna bastante participativa, que escrevia belissimamente, estava ausente há mais de um mês da plataforma, apesar de minhas tentativas de contato online. Fui até a secretaria do curso e solicitei sua ficha. Com seu número em mãos, telefonei para ela. Disse do pesar que sentia pela sua ausência e ouvi um pedido de desculpas, com um desabafo da vivência de um problema médico. Combinamos que ela poderia seguir seu tempo de aprendizagem e que teria em mim o suporte necessário para trilhar este caminho. Com contentamento, vi a aluna terminar a disciplina e seguir para outro professor-tutor. Um caso parecido aconteceu, no mesmo curso, com uma orientanda de monografia, que não respondia às minhas mensagens via plataforma. Mais uma vez, solicitei o contato telefônico da aluna na secretaria. Ao ligar, soube que ela estava em estágio avançado de gravidez, em situação de risco. Montamos um cronograma diferenciado para ela e mantivemos os contatos telefônicos. Com felicidade, vi seu trabalho ser considerado um dos melhores do curso e encaminhado para uma publicação. Acredito que seja tarefa de qualquer professor, presencial ou à distância, lutar pelos seus alunos, apesar das dificuldades encontradas. A compreensão pela humanidade do outro, pelo seu tempo, pelo seu ritmo, pela sua individualidade, bem como a empatia, a abertura, o diálogo, a flexibilidade, são tão importantes quanto a colocação de limites e de prazos (MARIA, 2017).
\end{abstract}

No relato de Maria é possível identificar o modo como ela atua na relação com o outro, os meios que mobiliza para buscar estratégias pedagógicas que visem incentivar a maior participação das alunas em suas aulas, a reflexão de sua própria prática docente, além de adotar uma postura flexível na construção do planejamento educacional. Notamos que a docente online pauta suas ações na promoção constante da interatividade com as alunas (SILVA, 2009), acionando a participação delas nas atividades online com a intenção de incentivar maiores possibilidades de trocas de experiências no AVA. 
Observamos ainda que Maria visa mobilizar as experiências do conhecimento (SILVA, 2009), implementando situações de aprendizagem que levam em consideração as experiências das alunas. Não se trata de pensar a prática pedagógica de maneira isolada, mas utilizar as potencialidades comunicacionais das interfaces digitais para flexibilizar a forma com a qual o trabalho é desenvolvimento, encorajando todos os alunos a participar de processos de ensinar e aprender colaborativos que "encontram suas bases em princípios de confiança e de compartilhamento" (SANTAELLA, 2012, p. 36). A relação estabelecida entre Maria e seus alunos nos ajuda a entender a importância da mediação que a docente online faz, na qual ela atua não somente na construção do conhecimento, mas também no entendimento das problemáticas sociais que atravessam os cotidianos de cada um. Ao promover essa maneira de mediar, a profissional estabelece uma prática educativa horizontal com as alunas e aberta ao diálogo (FREIRE, 2005).

Os processos de ensino-aprendizagem mediados pelas tecnologias digitais em rede envolvem também o cuidado com o estabelecimento de uma postura ética que esteja sintonizada com as demandas sociais de cada turma. Conforme pontua Pretto (2010) sobre a importância da "cultura da liberdade" mediada pelos processos de interação na internet, é importante cultivarmos uma postura que envolva "a generosidade, a colaboração, a ética, o compartilhamento, a capacidade de ouvir para pode interagir" (PRETTO, 2010, p. 159). A $\mathrm{EaD}$, como todo processo educacional, não está somente atenta aos processos de produção de conhecimento, mas atenta, conforme frisou a tutora Maria, "pela humanidade do outro, pelo seu tempo, pelo seu ritmo, pela sua individualidade, bem como a empatia, a abertura, o diálogo, a flexibilidade, são tão importantes quanto a colocação de limites e de prazos" (MARIA, 2017). Dessa forma, agir eticamente na docência online implica um compromisso que reconhece a singularidade de cada dinâmica de interação no AVA e percebe o estudante não como aquele que é meramente produtor-consumidor de conhecimento, mas também é fruto de um determinado contexto sociocultural. O depoimento de Maria acima nos auxilia a pensar no quanto ainda precisamos colocar em xeque a reiteração constante de uma lógica que, historicamente, vem inserindo os profissionais do campo da educação num papel de meros executores de atividades pedagógica com fins avaliativos, desconsiderando a importância da linguagem no fortalecimento dos vínculos sociais e afetivos.

A seguir, D. K mostra o quanto seu trabalho é centralizado na forma com que a linguagem é empregada no cotidiano de sua experiência como docente online.

D. K: A linguagem emocional tem sido extremamente relevante na atual função que venho assumindo: a orientação de TCC por meio da EaD. Como o modelo institucional do trabalho de conclusão de curso [monografia] que venho orientando pressupõe parte do trabalho construído de forma colaborativa, muitas das vezes, conciliar perspectivas diversas de cursistas que não construíram um percurso juntos e não constituíram uma empatia e engajamento na mesma medida, é um desafio! Nessa busca por acionar a motivação do cursista para concluir o curso, muitas vezes adoto a linguagem emocional com mais ênfase no contato individual 
do que no coletivo. Explico: alguns alunos se sentem muito mais à vontade com a orientadora, em uma conversa reservada do que solicitando a sua intervenção no interior do trabalho do grupo. No início do trabalho em grupo busco incentivar esse modelo de comunicação, com vista a que os integrantes se relacionem de forma respeitosa e amistosa. Os primeiros contatos convergem nesse sentido. Entretanto, durante o percurso, estranhamentos próprios da falha da comunicação para conciliação e a necessidade de fazer prevalecer dada percepção, desconsiderando outras contribuições mais tímidas, instauram os primeiros conflitos, que fogem do fórum de discussão (espaço que eu posso acompanhar e planejar a mediação) para outros espaços externos ao ambiente do curso. Há ainda os alunos que possuem um ritmo de produção acadêmica diferente ou não possuem a mesma motivação para tamanha dedicação e se veem desolados no interior da produção coletiva. $O$ trabalho "nos bastidores" que adoto, instaurado na linguagem emocional visa inclusive acalmar os ânimos mais acirrados para a busca de alguma conciliação. Nem sempre é possível, mas na maior parte das vezes, pelo menos contribui para a permanência e conclusão do curso. É uma intervenção que muitas das vezes não fica registrada no espaço público do fórum, mas demanda enorme energia $e$ disponibilidade do profissional que assume essa perspectiva. Apesar de compor aspectos mediadores no espaço do não visível, é o que mais mobiliza a atenção e tempo do profissional. A linguagem emocional também deve estar presente nos feedbacks, inclusive quando se aponta problemas a serem superados em dada produção. Quando o feedback reflete um modelo tradicional/punitivo do equívoco, sem uma proposição de como pode-se melhorar, o aluno também vê-se desamparado e dificilmente buscará o apoio da orientação na perspectiva da linguagem emocional. É certamente uma necessidade para professores que atuam nas diversas modalidades, desenvolver essa postura. Mas na EaD, principalmente na mediação do trabalho colaborativo, é uma urgência! (D. K, 2017).

Observamos nesse relato que a docente faz uso da linguagem emocional em suas práticas mediadoras, adotando diferentes modos de se comunicar, analisando, a cada nova situação, como será o modo mais adequado, na concepção dela, de interagir com os alunos. Na prática educativa de D. K, conforme relatado, a profissional reconhece o quanto a linguagem ocorre "mediante ações consensualmente coordenadas, nas quais se levam em consideração os aspectos ontogênicos permeados pela emoção" (BRUNO, 2002, p. 85). De acordo com D. K, o aspecto emocional da linguagem é orientador de sua prática docente, principalmente no que concerne à maior implicação-participação de todos na construção de conhecimento no AVA.

Analisamos o quão importante é o fato de o docente fazer uso da linguagem emocional na mediação do trabalho pedagógico. Através dessa linguagem, é possível explorarmos os diferentes meios disponíveis no ambiente virtual para proporcionar um espaço acolhedor, incentivando todos a partilhar diferentes saberes. Dessa forma, passamos a conhecer um pouco da história de cada aluno na medida em que o trabalho vai sendo desenvolvido nos AVA. Ainda de acordo com Bruno (2002), o fator emocional fundamenta e sustenta o aspecto racional. Não há como dissociá-los. Não há racionalidade no ser humano sem a emoção. A emoção interfere na razão, com a linguagem e a razão permanecendo imbricadas e interdependentes com a emoção. 
Ainda no relato de D.K, compreendemos que a complexidade do processo de ensinaraprender em rede demanda da profissional outras possibilidades de atuação e de negociação, requer envolvimento com os cotidianos de seus alunos, a mediação de conflitos e de interesses, e o uso de uma comunicação afetuosa e individualizada para motivar o aprendente: "muitas vezes adoto a linguagem emocional com mais ênfase no contato individual do que no coletivo" (D. K, 2017). Por meio desse relato também, encontramos sinais daquilo que Alves (2001, 2003) e Oliveira (2007) vêm chamando a atenção ao fazer pesquisa com os cotidianos, a de analisar as (micro) práticas plurais dos sujeitos nas múltiplas demandas do dia a dia, que são as suas maneiras de fazer, para assim entendermos as lógicas que por ali operam.

Outro aspecto importante abordado por D.K é o cuidado que demonstrou ter nos feedbacks das atividades que os alunos produzem. Essa é uma etapa relevante do processo de ensinoaprendizagem, pois o retorno dado aos alunos é um fator determinante para que as futuras etapas do trabalho sejam (re) pensadas. Ao reconhecermos que "o homem é palavra, que o homem é enquanto palavra, que todo humano tem a ver com a palavra, se dá em palavra, está tecido de palavras, que o modo de viver próprio desse vivente, que é o homem, se dá na palavra e como palavra" (LARROSA, 2002, p. 21), não há como desconsiderar a importância do retorno que damos ao outro na forma de palavras. Na docência online, esse retorno, comumente designado de feedback, também ocorrer através do uso de palavras, evidenciando a centralidade das palavras na construção dos processos comunicacionais nos AVA. Nesse contexto, vale reiterar que a produção de sentidos envolvendo dois ou mais praticantes culturais só pode ser compreendida "no fluxo da cadeia de interação verbal" (RAMOS; SCHAPPER, 2010, p. 29).

O terceiro relato foi enviado por Cíntia e traça um paralelo entre a experiência dela enquanto docente online e enquanto aluna de um curso a distância.

Cíntia: Sou docente online na disciplina Informática na Educação, no curso de Licenciatura em Pedagogia da UERJ, e, ao mesmo tempo, aluna no curso a distância de Especialização em Planejamento, Implementação e Gestão da EaD (PIGEAD), na UFF. Como circulo nos dois espaços - como docente e como aluna online - tenho estado atenta ao uso de uma linguagem mais acolhedora com os alunos do curso de Licenciatura em Pedagogia. Vivenciei, como aluna no PIGEAD, tutores que promovem o silenciamento dos alunos, especialmente quando desejam manter o foco no cumprimento de instruções, prazos e tarefas. Qualquer assunto, nos fóruns, que pudesse gerar um debate um pouco mais polêmico ou que promovesse a expressão de ideias divergentes (dentro do assunto abordado) era rapidamente reprimido ou silenciado por alguns professores. Tal observação fez com que eu, enquanto docente online no curso de Licenciatura, buscasse me expressar nos fóruns de maneira exatamente oposta: mesmo diante da necessidade de se mediar o assunto central do debate, tenho procurado manter uma atitude acolhedora às postagens que venham a enriquecer, questionar, contradizer ou contra argumentar as ideias expostas. Percebo que isso promove maior aproximação da tutoria a distância com o aluno, que se sente mais confortável para expressar suas impressões sobre o conteúdo trabalhado, passa a entender que os fóruns são flexíveis e abertos à convergência e à divergência de ideias. $O$ bom 
resultado de maior aproximação é notório tanto nas avaliações presenciais e a distância, como em uma comunicação mais reservada numa troca gentil de mensagens, por exemplo (CÍNTIA, 2017).

Ao relatar sua experiência como aluna de $\mathrm{EaD}$, Cíntia menciona práticas realizadas pelos docentes online do curso que nos remeteram a "educação bancária" tão problematiza por Paulo Freire (2005). Partimos do pressuposto que essas práticas são transposições didáticas do ensino presencial massivo para o online, nas quais o currículo já está definido e fechado, o conteúdo é foco do processo educativo, não há interatividade e nem partilhas de experiências entre docente-alunos e alunos-alunos. A docência, por sua vez, não possibilita abertura ao novo e promove o silenciamento em sala de aula.

Por outro lado, quando atua como docente no AVA, Cíntia promove práticas diferentes daquelas que a formaram, sendo suas práticas voltadas para a mediação colaborativa. Ao buscar promover práticas pedagógicas que visem maiores possibilidades de enriquecimento/questionamento por parte dos alunos, Cintia percebe "maior aproximação da tutoria a distância com o aluno, que se sente mais confortável para expressar suas impressões sobre o conteúdo trabalhado, passa a entender que os fóruns são flexíveis e abertos à convergência e à divergência de ideias". Dessa forma, Cintia se alinha com uma perspectiva metodológica que busca ensejar no AVA "o desdobramento da conversação, ora aprofundando o que está sendo discutido, ora ampliando o debate com outras fontes de informação" (SANTOS; CARVALHO; PIMENTEL, 2016, p. 39). Com isso, Cintia tem a oportunidade de intercambiar novas experiências ao incentivar a partilha de pontos de vistas distintos.

A comunicação escrita é o principal meio utilizado pelos docentes online para interagir com os alunos nos AVA. Lévy (1999), há quase duas décadas, já previa que o ciberespaço se tornaria o principal canal comunicacional do século XXI. É através do ciberespaço - essa rede gigantesca de transmissão e acesso (SANTAELLA, 2012) - que internautas de todos os cantos do globo reúnem-se para participar de processos de interação. Neste contexto mediado pelas tecnologias digitais em rede, a palavra de ordem é comunicação. Através das interfaces digitais, a escrita vem se materializando nos processos comunicacionais interativos entre estudantes e docentes online, o que revela o quanto a palavra escrita é importante na educação online porque ela expressa os aspectos emocionais da linguagem.

\section{BREVES CONSIDERAÇõES FINAIS}

Com os relatos produzidos na pesquisa apresentada neste artigo, foi possível refletirmos sobre questões relacionadas à prática pedagógica cotidiana de docentes online, os usos que fazem da linguagem emocional com seus alunos, a preocupação com a interação deles na disciplina, como também a importância da mediação nos estranhamentos e tensões no processo 
formativo. Por outro lado, é preciso ressaltar que o desenvolvimento da $\mathrm{EaD}$ no cenário educacional brasileiro demanda formação continuada de qualidade para assegurar que os objetivos propostos em cada curso sejam alcançados, propiciando que os processos de ensinoaprendizagem mediados pelas interfaces digitais contribuam para a prática profissional dos estudantes.

Essa pesquisa, ao investigar as implicações teórico-práticas da linguagem emocional na docência online, ofereceu um aporte teórico que foi se aproximando da prática vivenciada nos AVA pensando no fortalecimento das relações interpessoais entre os atores evolvidos nesse processo. Em relação aos procedimentos metodológicos, apresentamos o modo como foram realizadas as conversas iniciais com os docentes online, assim como citamos alguns trechos das contribuições com os relatos de pesquisa de suas práticas.

Assim, abordamos inúmeros aspectos da educação online, modalidade educacional situada num cenário sócio-técnico envolvendo a produção de conhecimento a partir do uso de interfaces comunicacionais digitais por usuários geograficamente dispersos. Somando-se a isso, demonstramos que o docente deve caminhar com esses progressos tecnológicos e se apropriar do digital em rede com a intenção de potencializar seu papel mediador na educação online.

Mediar processos educacionais nos AVA através do uso da linguagem emocional implica estarmos atentos aos momentos de interação criados em colaboração com os estudantes. Isso significa reconhecermos a importância de permanecermos implicados no desafio de escutar atentamente cada palavra enunciada e cada momento de silêncio que eventualmente é desencadeado. A linguagem é um verdadeiro convite para que possamos aprender-ensinar com o outro nos AVA, por isso é grande nossa responsabilidade ética na docência online, porque nos faz (re)pensar cotidianamente o quanto o envolvimento emocional é constituinte das relações humanas.

\section{REFERÊNCIAS}

ALVES, Nilda. Sobre os movimentos das pesquisas nos/dos/com os cotidianos. Revista Teias, Rio de Janeiro, v. 4, n. 7, 2003. Disponível em: < http://www.epublicacoes.uerj.br/index.php/revistateias/article/view/23967/16939>. Acessado em: 25 de maio. 2018.

ALVES, Nilda. Decifrando o pergaminho - o cotidiano das escolas nas lógicas das redes cotidianas. In: OLIVEIRA, Inês Barbosa; ALVES, Nilda . Pesquisa no/do cotidiano das escolas - sobre redes de saberes. Rio de Janeiro: DP \& A, 2001. 168 p. (Vida cotidiana e Pesquisa em Educação). ISBN 978-85-60985-32-6 
ARRUDA, Eucidio. Relações entre tecnologias digitais e educação: perspectivas para a compreensão da aprendizagem escolar contemporânea. In: FREITAS, Maria Teresa de Assunção. Cibercultura e formação de professores. Belo Horizonte: Autêntica, 2009. 120 p. ISBN 978-85-75264-17-1

BAKHTIN, Mikhail. Estética da criação verbal. Tradução de Paulo Bezerra. 6. Ed. São Paulo: Martins Fontes, 2011.478 p. ISBN 978-85-78274-70-2

BENTO, Nanci; VENAS, Ronaldo. Usos do aplicativo Hand Talk na aprendizagem da Língua Brasileira de Sinais. In: COUTO, Edvaldo; PORTO, Cristiane; SANTOS, Edméa. App-learning: experiências de pesquisa e formação. Salvador: EDUFBA, 2016. 252 p. ISBN 978-85-232-1533-0

BONILLA, Maria Helena Silveira. Escola aprendente: comunidade em fluxo. In: FREITAS, Maria Teresa de Assunção . Cibercultura e formação de professores. Belo Horizonte: Autentica, 2009. 120 p. ISBN 978- 85- 75264-17-1

BRUNO, Adriana Rocha. A linguagem emocional em ambientes telemáticos: tecendo a razão e a emoção na formação de educadores. Dissertação (Mestrado - Programa de PósGraduação em Educação: Currículo). Pontifícia Universidade Católica de São Paulo, São Paulo, 2002.

CASTELLS, Manuel. Redes de indignação e esperança: movimentos sociais na era da internet. Tradução de Carlos Alberto Medeiros. Rio de Janeiro: Zahar, 2013. 271 p. ISBN 978-85-378-1110-8

COUTO JUNIOR, Dilton Ribeiro. Cibercultura, juventude e alteridade: aprendendoensinando com o outro no Facebook. Jundiaí: Paco Editorial, 2013. 164 p. ISBN 978-858148180-7

FERREIRA, Helenice Mirabelli Cassino. Dinâmicas de uma juventude conectada: a mediação dos dispositivos móveis nos processos de aprender-ensinar. 2014. 272f. Tese (Doutorado em Educação) - Faculdade de Educação, Universidade do Estado do Rio de Janeiro, Rio de Janeiro, 2014.

FREIRE, Paulo. Pedagogia do oprimido. 40 Ed. Rio de Janeiro: Paz e Terra, 2005. 216 p. ISBN 8521900058

GERALDI, João Wanderley. Bakhtin tudo ou nada diz aos educadores: os educadores podem dizer muito com Bakhtin. In: FREITAS, Maria Teresa de Assunção. Educação, arte e vida em Bakhtin. Belo Horizonte: Autêntica Editora, 2013. 112 p. ISBN 9788582171233

JENKINS, Henry. Cultura da convergência. Tradução de Susana Alexandria. 2 Ed. São Paulo: Aleph, 2009. 432 p. ISBN 9788576570844 
LARROSA, Jorge. Notas sobre a experiência e o saber de experiência. Revista Brasileira de Educação, n. 19, 2002. Disponível em: < http://www.scielo.br/pdf/rbedu/n19/n19a02.pdf>. Acessado em: 25 de maio. 2018.

LEMOS, André. Cibercultura: tecnologia e vida social na cultura contemporânea. Porto Alegre: Editora Sulina, 2002. 295 p. (Coleção Cibercultura). ISBN 978-85-205-0577-9

LEMOS, André. Os sentidos da tecnologia: cibercultura e ciberdemocracia. In: LEMOS, André; LÉVY, Pierre. $O$ futuro da internet: em direção a uma ciberdemocracia planetária. São Paulo: Paulus, 2010. 258 p. (Coleção Comunicação). ISBN 978-85-349-3181-6

LEMOS, André; LÉVY, Pierre. O futuro da internet: em direção a uma ciberdemocracia planetária. São Paulo: Paulus, 2010. 258 p. (Coleção Comunicação). ISBN 978-85-349$3181-6$

LÉVY, Pierre. Cibercultura. Tradução de Carlos Irineu da Costa. São Paulo: Editora 34, 1999. 264 p. (Coleção TRANS). ISBN 84-7326126-9

MERCADO, Luís Paulo Leopoldo. Pesquisa qualitativa on-line utilizando a etnografia virtual. Revista Teias, Rio de Janeiro, v. 13, n. 30, 2012. Disponível em: < http://www.epublicacoes.uerj.br/index.php/revistateias/article/view/24276/17255>. Acessado em: 25 de maio. 2018

NETO, Antônio Oliveira; VERSUTI, Andrea; VAZ, Wesley. Perspectivas para o uso do Whatsapp Messenger no estímulo à aprendizagem dos sujeitos. In: COUTO, Edvaldo; PORTO, Cristiane; SANTOS, Edméa. App-learning: experiências de pesquisa e formação. Salvador: EDUFBA, 2016. 252 p. ISBN 978-85-232-1533-0

OLIVEIRA, Carloney Alves; MERCADO, Luís Paulo Leopoldo. Ensino de matemática utilizando o aplicativo QR Code no contexto das tecnologias móveis. In: COUTO, Edvaldo; PORTO, Cristiane; SANTOS, Edméa. App-learning: experiências de pesquisa e formação. Salvador: EDUFBA, 2016. 252 p. ISBN 978-85-232-1533-0

OLIVEIRA, Inês Barbosa. O campo de estudos do cotidiano e sua contribuição para a pesquisa em educação. In: SCHWARTZ, Cleonara Maria et al. Desafios da educação básica e pesquisa em educação. Vitória: EDUFES, 2007.

PRETTO, Nelson De Luca. Professores universitários em rede: um jeito hacker de ser. Motrivivência, Florianópolis, ano XXII, n. 34, 2010. Disponível em: <https://periodicos.ufsc.br/index.php/motrivivencia/article/view/16038/15850>. Acessado em: 25 de maio. 2018

PRETTO, Nelson De Luca; BONILLA, Maria Helena Silveira. Construindo redes colaborativas para a educação. Belo Horizonte/MG, 2008. 
PRIMO, Alex. Interações mediadas e remediadas: controvérsias entre as utopias da cibercultura e a grande indústria midiática. In: PRIMO, Alex. Interações em rede. Porto Alegre: Editora Sulina, 2013. 279 p. ISBN 9788520506837.

RAMOS, Bruna Sola; SCHAPPER, Ilka. (Des)atando os nós da pesquisa na abordagem histórico-cultural. In: FREITAS, Maria Teresa de Assunção; RAMOS, Bruna Sola (Orgs.). Fazer pesquisa na abordagem histórico-cultural: metodologias em construção. Juiz de Fora: Ed. UFJF, 2010, 196 p. ISBN 9788576720928

RECUERO, Raquel. Atos de ameaça à face e à conversação em redes sociais da internet. In: PRIMO, Alex (Org.). Interações em rede. Porto Alegre: Editora Sulina, 2013. 279 p. ISBN 9788520506837.

RECUERO, Raquel. A conversação em rede: comunicação mediada pelo computador e redes sociais na internet. Porto Alegre: Sulina, 2012. 238 p. ISBN 9788520506509

SANTAELLA, Lucia. Da cultura das mídias à cibercultura: o advento do pós-humano.

Revista FAMECOS, Porto alegre, n. 22, 2003. Disponível em:

<http://revistaseletronicas.pucrs.br/ojs/index.php/revistafamecos/article/viewFile/3229/2493> . Acessado em: 25 de maio. 2018

SANTAELLA, Lucia. A tecnocultura atual e suas tendências futuras. Signo y Pensamiento, v. 30, n. 60, p. 30-43, 2012. Disponível em:

<http://revistas.javeriana.edu.co/index.php/signoypensamiento/article/download/2408/1692>. Acessado em: 25 de maio. 2018

SANTAELLA, Lucia; LEMOS, Renata. Redes sociais digitais: a cognição conectiva do Twitter. São Paulo: Paulus, 2010. 144 p. ISBN 9788534932394.

SANTOS, Edméa. Educação online como campo de pesquisa-formação: potencialidades das interfaces digitais. In: SANTOS, Edméa; ALVES, Lynn. Práticas pedagógicas e tecnologias digitais. Rio de Janeiro: E-papers, 2009. 328 p. ISBN 85-76500-83-3

SANTOS, Edméa. A cibercultura e a educação em tempos de mobilidade e redes sociais: conversando com os cotidianos. In: FONTOURA, Helena Amaral; SILVA, Marco (Org.). Práticas pedagógicas, linguagem e mídias: desafios à Pós-graduação em Educação em suas múltiplas dimensões. Rio de Janeiro: ANPEd Nacional, 2011.

SANTOS, Edméa. Educação online para além da EAD: um fenômeno da cibercultura. In: SILVA, Marco; PESCE, Lucila; ZUIN, Antonio (Org.). Educação online: cenário, formação e questões didático- metodológicos. Rio de Janeiro: Wak, 2010, 384 p. ISBN 978-85-7854093-7

SANTOS, Edméa. Formação de professores e cibercultura: novas práticas curriculares na educação presencial e a distância. Revista da FAEEBA - Educação e Contemporaneidade, Salvador, v. 11, n. 17, 2002. Disponível em: 
<http://www.ufjf.br/grupar/files/2014/09/Formacao_de_professores_e_Cibercultura.pdf >. Acessado em: 25 de maio. 2018

SANTOS, Edméa; CARVALHO, Felipe Silva Ponte; PIMENTEL, Mariano. Mediação docente online para colaboração: notas de uma pesquisa-formação na cibercultura. ETD Educação Temática Digital, Campinas, v. 18, n. 1, 2016. Disponível em:

$<$ https://periodicos.sbu.unicamp.br/ojs/index.php/etd/article/view/8640749/12238>. Acessado em: 25 de maio. 2018

SILVA, Marco. Formação de professores para a docência online. In: CONGRESSO INTERNACIONAL GALEGO-PORTUGUÊS DE PSICOPEDAGOGIA, 10., 2009, Braga. Actas do...]. Braga: Universidade do Minho, 2009. ISBN- 978-972-8746-71-1

\section{${ }^{\mathrm{i}}$ Sobre os autores \\ ${ }^{1}$ Caroline Costa Nunes Lima}

E-mail: carolinecnunes52@gmail.com

Universidade do Estado do Rio de Janeiro - Brasil

Especialista em língua portuguesa pela FAMA e Especialista em planejamento, implementação e gestão em EaD pela Universidade Federal Fluminense (UFF).

\section{${ }^{2}$ Felipe da Silva Ponte de Carvalho}

E-mail: felipesilvaponte@gmail.com

Universidade do Estado do Rio de Janeiro - Brasil

Doutorando em Educação da Universidade do Estado do Rio de Janeiro [UERJ].

\section{${ }^{3}$ Dilton Ribeiro Couto Junior $(\mathbb{D}$}

E-mail: junnior 2003@yahoo.com.br

Universidade do Estado do Rio de Janeiro - Brasil

Pós-doutorando em Educação da Universidade do Estado do Rio de Janeiro [UERJ]. 